\title{
USALSIM: Learning, Professional Practices and Employability in a 3D Virtual World
}

\author{
Emiliana Pizarro Lucas*, Juan Cruz-Benito, \\ Service of Professional Insertion, Practices and Employment \\ University of Salamanca \\ Patio de Escuelas 1, 37008 Salamanca, Spain \\ Email:mili@usal.es \\ Email: juancb@usal.es \\ *Corresponding author \\ Óscar Gil Gonzalo \\ Pro Vice-Chancellor Office for Innovation and Infrastructures \\ University of Salamanca \\ Patio de Escuelas 1, 37008 Salamanca, Spain \\ Email: oscar.gil@usal.es
}

\begin{abstract}
USALSIM is a project developed by the University of Salamanca as a response to the policy changes of learning and work placements in the new European Space for Higher Education, funded by the Spanish Ministry of Education and inscribed within an innovation program regarding the employability of university students (CAIE059). The contribution of USALSIM is concerned with how to face the increase in the number of students who will participate in the different university work placement programs and the increasing number of companies and institutions necessary to host and train theses students. This project uses a 3D virtual environment (a work placement simulator) that creates a virtual representation of different work environments and allows students to acquire professional skills. Representing a professional workspace such as a laboratory, for example, the student can simulate common tasks through active learning. This virtual world is focused on a constructive pedagogy, whereby students are directly involved in their formative development, establishing professional relationships, developing transversal and technical competencies, and evaluating their knowledge.
\end{abstract}

Keywords OpenSimulator, Employability, E-learning, Work Space, Practices, Virtual World, Moodle, Sloodle, Professional Skills, USALSIM, Technology Enhanced Learning

\section{Introduction}

There are different definitions of what constitutes a virtual world and what its primary characteristics are. According to (Schroeder, 1996) and (Schroeder, 
2008), a virtual world environment is "[a]computer-generated display that allows or compels the user (or users) to have a sense of being present in an environment other than the one they are actually in, and to interact with that environment".

Over the last decade there have been several studies regarding the advantages of multi-user virtual environments for teaching, due to their relationship with the concept of experiential learning. According to Kolb's theory of experiential learning (Kolb et al., 2002), it is possible for the learner to gain experience and deeper knowledge by experiencing the four-stage learning cycle, which consists of: Concrete Experience, Reflective Observation, Abstract Conceptualization, and Active Experimentation. Other experts such as (Barab et al., 2005) and (Dalgarno et al., 2009) assert that the potential of 3D virtual worlds is rooted in the possibility of offering more student-centred learning processes, which require students to be more committed by relying on experiential activities.

The USALSIM project aims to respond to the needs related to professional training and work placement for undergraduates in the University of Salamanca. It is focused on resolving the difficulties of finding companies to develop the work placement program, and coordinating school and work schedules. Using a "training simulator", we intend to expand existing possibilities by representing occupations and professional relationships that replicate daily activities, so that students can enhance their own training.

In the case of professional work placements that are developed outside the educational centre, USALSIM permits a mixed model that combines the training received in a virtual space with that developed in a real workspace, serving, in some cases, as a pre-professional training program, and in others as complementary training to an existing job. The training is supervised by a workplace mentor and an academic advisor, in addition to the collaboration of a professional guidance counsellor. This enables students to use virtual reality to learn tasks that will be physically carried out both in a work placement environment and throughout their professional career. The tool enables complementing the hours worked in the company during the work placement, and functions as an evaluation device for the academic advisor and mentor, an extension of the theoretical and practical syllabus, an assistant to the student's entrance into the workforce, or a demonstration of a new experience in social interaction, etc.

From an educational perspective, USALSIM will serve both to assist and complement specific activities that are occasionally unfeasible to carry out within the University. The project can provide spaces that are not always available in real life, making it viable for students to prepare themselves or train before engaging in specific processes or activities, and also provide environments that can be used for meetings, work exhibits, conferences, etc.

This paper aims to review the basic concepts used in the development of the $3 \mathrm{D}$ environment of USALSIM, a review of the state-of-art, the main technologies and the conclusions of the study. Section 2 describes the project goals and some theoretical background about employability and professional skills. Section 3 presents a brief comparison between the main options available today to develop virtual worlds, explaining their basic concepts. Section 4 describes the basic technologies used and the defined functional structure created for the simulation environment. 
Section 5 presents the test that was carried out, and evaluation phase of the project. Finally, section 6 describes the conclusions and future steps required to carry on with the USALSIM project.

\section{Goals}

Prior to the development of the system, it was necessary to propose the educational methodology that would be applied, and to define the goals associated with the project's execution. These will form the theoretical basis of the USALSIM system.

The main goals of the platform are:

To develop an educational and practical tool for the University Community, adapted to its needs.

To give students the opportunity to complete professional practice hours in a workplace through a Virtual World, in response to the new educational curriculum in the context of the European Higher Education Space.

To encourage the practical training for students in a risk-free environment. This environment is very useful for providing the student with previous contact in the subject or field of study prior to actual engagement in the profession.

To promote the practical training of the students, placing special attention on the development of their professional skills, thus improving their chances of insertion in the labour market, and enabling them to be more competitive in a professional environment.

To complete or strengthen real professional experience.

Professional skills are formally defined as: "The real training to solve certain problems" (Serón, 1999). USALSIM tries to develop the most useful professional skills for the students:

Self-awareness: self-confidence refers to the perception of being effective (selfefficacy) to perform a task, take responsibility or face critical challenges in different areas (work, family, health, etc.) (Pita and Pizarro, 2013) (Hernández-Fernaud et al., 2011). The USALSIM project promotes this professional competence by providing feedback on the tasks carried out by the users, and positive reinforcement for tasks well done.

Analysis, Synthesis and Critique: analysis is the method of reasoning that makes it possible to deconstruct complex situations into parts, while synthesis is the composition of a whole by the joining of its parts (Pita and Pizarro, 2013) (Castillo Ceballos and Rodríguez Sedano., 2011). This professional competence is developed by requiring users to participate in phases of discussion and critique (individually and in groups) for all activities and practices developed within the virtual environment. 
Organization and planning: these refer to the ability to define priorities when performing tasks, and establish action plans through the optimal use of time, means and resources (Pita and Pizarro, 2013) (Dalziel et al., 1996). This competence is inherent to all the activities in our Educational Virtual World given that the students should at all times organize and plan the execution of the various.

Communication skills: communication is a strategic tool in one's personal and professional life (Mestres i Salud, 2013) (Pita and Pizarro, 2013). Students should discuss and resolve various tasks as a group, in some cases, and individually in others. Moreover, they should report to the task leader and defend their ideas. This exchange allows the development of communication, as a professional competence.

Responsibility and perseverance: responsibility refers to the ability to recognize and accept the consequences of our acts (Zapata Ros, 2005). Perseverance is constancy, firmness and tenacity in carrying out an action (Pita and Pizarro, 2013) (Goleman, 2012). This specific professional competence is developed in USALSIM through the process of resolving various tasks in incremental phases. Student activity is divided into different phases with varying degrees of difficulty in the resolution process. This requires students to demonstrate perseverance in their effort to reach the proposed objectives.

Decision-making (working independently): is the ability to identify and analyse problems that require taking action, making the most of opportunities, or facilitating the resolution of problems (Alles, 2005). In the professional world, it is so important to have strong decision-making and learning skills in order to recognize the significance of each decision that is taken (Pita and Pizarro, 2013). This competence is strongly connected with the previous competence of acquiring selfconfidence.

Teamwork and Collaboration: a team is a group of individuals that cooperate to achieve a common goal. Teamwork is regarded as one of the keys to success in any organization (Pita and Pizarro, 2013) (Accenture and Universia, 2007) (Martínez and Salvador, 2005). This competence is related to the previous one on communication.

Learning capacity and collaboration: related to the capacity of continuous learning throughout life and attitudinal aspects or personality in a broad sense. It is essential in the new European graduates (Pita and Pizarro, 2013) (Forrier and Sels, 2003) (Rodríguez et al., 2010).

Flexibility and change orientation: flexibility is the ability to understand and appreciate different perspectives of a situation, to adapt and work effectively. It is very important and valuable, since it allows companies to adapt to the competitive environment in which they find themselves (Pita and Pizarro, 2013) (Alles, 2007). This professional competence, unlike the others, involves a more technological than social context within USALSIM. The implementation of the professional practices, which include various decision-making paths and arbitrary conflict reso- 
lution phases for each task, requires students to be willing to evaluate their own conduct and adapt to the new conditions imposed by the system.

Achievement Motivation: The motivation for achievement is a boost to overcome challenges, progress and grow personally, socially and professionally. It is a multidimensional concept of competences and standards of excellence that creates a desire of establishing and realizing our objectives (Pita and Pizarro, 2013). Positive reinforcement is provided through messages sent within the virtual world when the student solves a problem, or by the activity leader when the student accomplishes a task correctly. This action keeps students motivated, encouraging them to find a solution whenever necessary and to do so with a positive attitude.

Conflict Resolution and Negotiation Techniques: conflict is common in our lives, so we have to accept it and manage it in the most effective way possible. Negotiation is the tool that allows us to resolve these conflicts (Pita and Pizarro, 2013) (Covey, 1999). Resolving a problem in a team environment or being accountable to a team leader requires the student to be able to resolve problems in very different types of situations. This forces the student to acquire a set of competences and mechanisms to resolve problems in a situation where the different parties are incapable of arriving easily at an understanding.

Clearly, the ability for students to obtain different abilities and competencies does not require a purely technological environment focused on task resolution. However, it is very important to design this process correctly from the point of view of user behaviour for the different tasks, and for the system to include a series of mechanisms that encourage communication and feedback of user actions. Moreover, the system must be able to reproduce human communicative and collaborative abilities as closely as possible, as well as discussion and understanding of the results.

\section{A brief comparison between Virtual Worlds}

During the USALSIM design phase, different 3D Virtual Worlds platforms were considered:

Second Life (SL) is a 3D virtual world, developed by Linden Lab, of Linden Research, Inc. Its users (residents) can access the world by using one of its multiple interfaces (viewers), which allow them to interact with other users through an avatar, participating in individual and group activities. The program access requires creating an account (Second Life, 2013). Its second most important appeal is the possibility of creating objects and exchanging virtual products through an open market, using the Linden Dollar (L\$). Second Life includes a 3D tool based on simple geometric figures, which allows building virtual objects. It has its own programming language, LSL (Linden Script Language), to add functionality to the 
objects. More complex objects, textures, animations and gestures can be externally created and then imported into SL. The Terms of Service of SL (TOS) claimed retention of copyright by the creators of the objects, while Linden Labs provided simple management features. Recent changes in the TOS have removed many of the creators' rights, setting Linden Labs as the owner of all the software available on their servers, and removing the creators' right of having a closed environment (Second Life Terms of Service, 2013).

Unit $3 D$ is a multiplatform game engine created by Unity Technologies, which supports integration with 3D design tools such as $3 d s$ Max, Maya, Softimage, Blender, etc. This engine uses different platforms, graphic rendering and effects creation, depending on the operating system, and allows the creation of $3 \mathrm{D}$ content that can be run natively on any supported platform (Unity3D, 2013). This software, whose basic version is free, offers a pro-version that provides plugins for the creation and adaptation of content to various platforms and operating systems. This game engine has been used in recent years for building Virtual Learning Worlds (W. Thompson, 2011) (Wang et al., 2010), due to the possibilities of creating, building and customizing virtual environments, in addition to its crossplatform feature.

OpenSimulator is a software platform that is used for the creation of multi-user and multi-platform $3 \mathrm{D}$ virtual worlds. It is open source, and is supported by a large community of users. It works similarly to Second Life, supporting Second Life protocols such as the SL communication protocol. In addition, viewers used to accessing Second Life generally adapt easily to this platform (OpenSimulator, 2013). Additionally, OpenSim avoids some important disadvantages characteristic of other platforms:

Property of creation: any object created in Second Life is not the exclusive property of the author, because Linden Lab, the owner of the platform, has rights over any object created in the platform. This means that at any time, the developers can leave the ownership of the project.

Property of the databases and user data: the databases and user data of Second Life, are under the domain of the owner company, so any eventuality can happen without having control over their user data and a lack of privacy.

Cost: OpenSim is a free and open platform. Consequently, it is possible to adapt the platform according to our needs, or to contribute to the development, which is a great advantage for large projects. The only costs that may be incurred are related to the adaptation of certain custom components, or to hiring external services such as voice artists (VoIP) or the management of personal data.

In order to develop a project like USALSIM, it is best to use a system that is capable of adapting components according to observed needs, and with controlled costs. For example, in order to have different spaces in Second Life, which would be required to create the professional practices, it is necessary to be a Premium us- 
er and to pay a variable cost according to the portion of land that is available. With Unity it is also necessary to purchase a number of software packages, although in this case only one payment is required at the beginning of the project. However, with OpenSim (Open Simulator, 2013) it is not necessary to invest large quantities of money in software; instead it requires an investment of the time and human resources needed to develop the system, configure our own servers and adapt the software to our specific needs. Information control is an important aspect of this type of project. For this reason, the ideal situation is for the University to have absolute control over the user data and professional practices carried out in the virtual world. This is why, from the beginning of the project, we selected the OpenSim platform as the best long term option (cost, adaptability and scalability) to develop the World of Professional Practices and Learning

\section{Developing the USALSIM virtual world}

USALSIM is a 3D virtual world that represents the most common workspaces of five professional areas (Pharmacy, Law, Biology/Biotechnology, Chemistry, and Humanities). For each of these areas, different professional positions and their associated tasks have been represented. They allow the students to be trained within these professional environments and to acquire the needed professional skills.

The OpenSimulator application server was used to develop the virtual environment. As previously explained, this software is used to create 3D multi-user and multi-platform virtual worlds. It is open code and is supported by a large user community.

Through OpenSimulator (OpenSim), the 3D virtual world is organized according to regions, or patches of land, which could be an island, a country or a megaregion. The architecture of the USALSIM project is organized according to islands. Five regions (islands) were built, each one corresponding to a title or branch of knowledge, and all joined to a sixth island representing the Service of Professional Integration, Work Placement and Employment of the University of Salamanca, the department that manages the project.

For each region or island, a set of Training Tasks and Learning Objects (Zapata Ros, 2005) (Arechabaleta, 2005), both educational and professional, were developed. These tasks and objects were designed with the cooperation of educators and professionals in the respective fields. Once it was designed, the training content was adapted to the technical and functional requirements of the simulator. Three types of training were identified:

Informative training, which provides students with the theoretical base needed to perform other tasks.

Procedural training, which prepares or trains the student to deal with procedures or activities during the training period. 
Immersion training, which accurately imitates the reality the student may face in a working environment, and prepares the student to deal with life-like situations in the simulator.

The objective was to create situations and contexts that force the student to make decisions, work as a team, be aware of the importance of the organization, manage personal resources, etc. (Pizarro and Cruz, 2012).

The functional architecture of the USALSIM virtual world was defined by taking into account the different Trainings Tasks and Learning Objects designed for each "island of knowledge". This architecture is based on three standard practice models, defined by a set of entries, exits, objects and connections among objects. Each training model defines the effect derived from the user action virtual objects, considering a set of pre-conditions and post-conditions. On that basis, the training models are distinguished as follows:

Distributed training model: According to (Tanenbaum and Van Steen, 2008) a distributed system is a collection of independent computers that give the user the impression of constituting a coherent system. In this model, the "Distributed System" is not a collection of computers, but of three-dimensional objects (laboratory equipment, etc.) that autonomously execute a series of tasks and interact among themselves in a distributed way to develop the training performed by the user. Each 3D object (peer) communicates to the others the result of the internal operation produced by the user action or the action of another object. In this horizontal communication, all peers are alerted to any communication from the others. In this case, a single object does not coordinate or become the center of communication. As a result, all objects of a defined area can be continuously updated, so that a high volume of interaction will not produce a bottleneck or inactivity due to the lack of information in any object of this area. This 3D-object-distributed architecture is based on a graph structure (figure 1), which is a set of objects (vertexes) joined by links (artists) representing binary relationships among the set of elements.

This training model presents a potential problem: all objects contain most of the training logic, which implies that an object with a high level of interaction can work at a slower processing speed. Additionally, this architecture allows the training to continue, even if a node fails, as long as it is not critical for the execution.

Star training model: a single object coordinates the relationships among the other training elements in this topology. Each communication goes through this object, and it decides on its own what to do with the incoming information. This topology is applied in training sessions where the collaborative process is strictly defined and has a determined sequence, so that the number of relationships among objects is small. In this way, there are satellite objects with a low execution load and an object that contains all the logic of the training and makes decisions regarding the global process. 
Role-playing training model: training content and resolutions can only be reached by interacting with other users (avatars). For instance, the Law training includes exercises related to judicial processes (figure 2), which would have to be simulated in a classroom environment since real courthouses are not available to conduct this activity. Thus, virtual spaces representing a courtroom were developed in order to create an immersion style training as close as possible to a real-life environment, even including the appropriate attire. These trainings require interaction among various users playing the different roles involved in the judicial process.

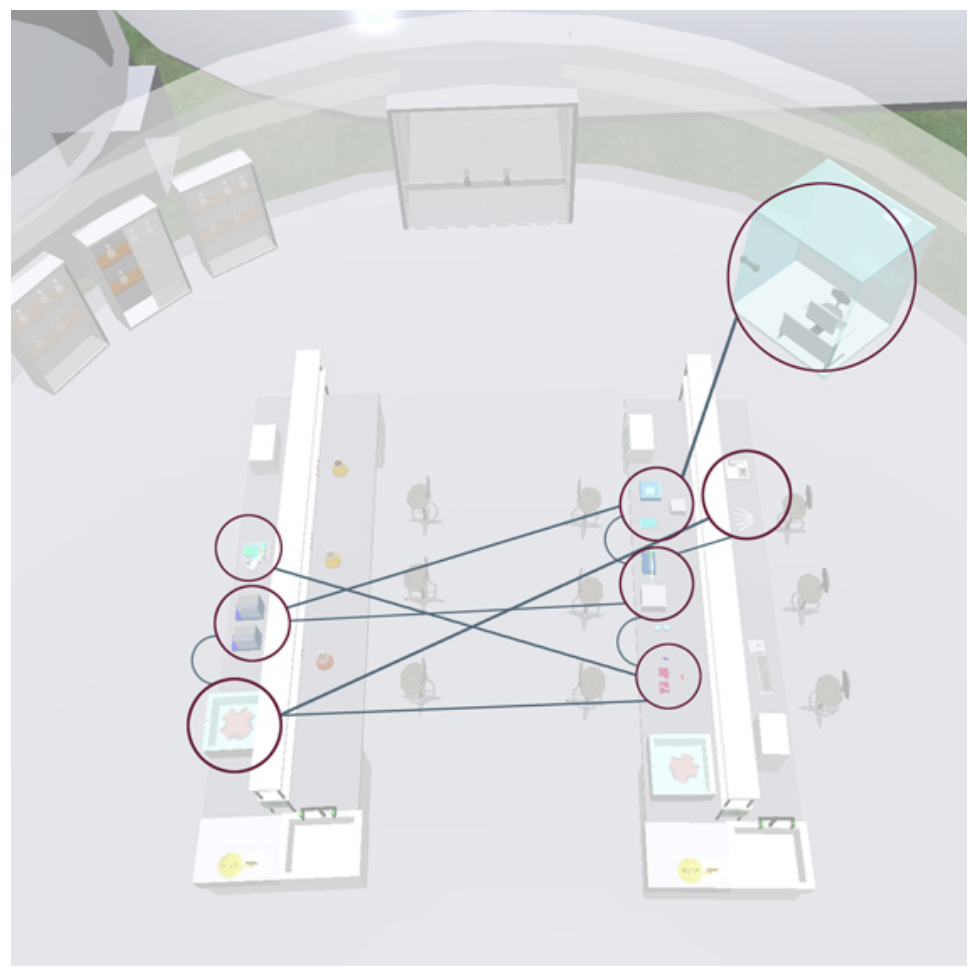

Fig. 1. Visualization of the object relationships in a training set

In this training model there is no definite execution for a set of $3 \mathrm{D}$ objects. Users have a set of interactive tools to develop their training, which are, essentially, communication tools such as text or voice. Additionally, users may have access to interactive screens, video players, screens for presentations, etc.

From the beginning of this project, one of the specific requirements established by designers of Virtual World and teachers from the University of Salamanca, was the ability to connect with the Moodle platform (Moodle, 2013). This platform is used as both a virtual-learning tool and a support tool for in-class learning in the University of Salamanca. Given that USALSIM is an education tool, there are 
several advantages to integrating these complementary platforms. The Sloodle (Sloodle, 2013) project is an open code project that permits the integration of multi-user virtual environments OpenSim and the Moodle system.

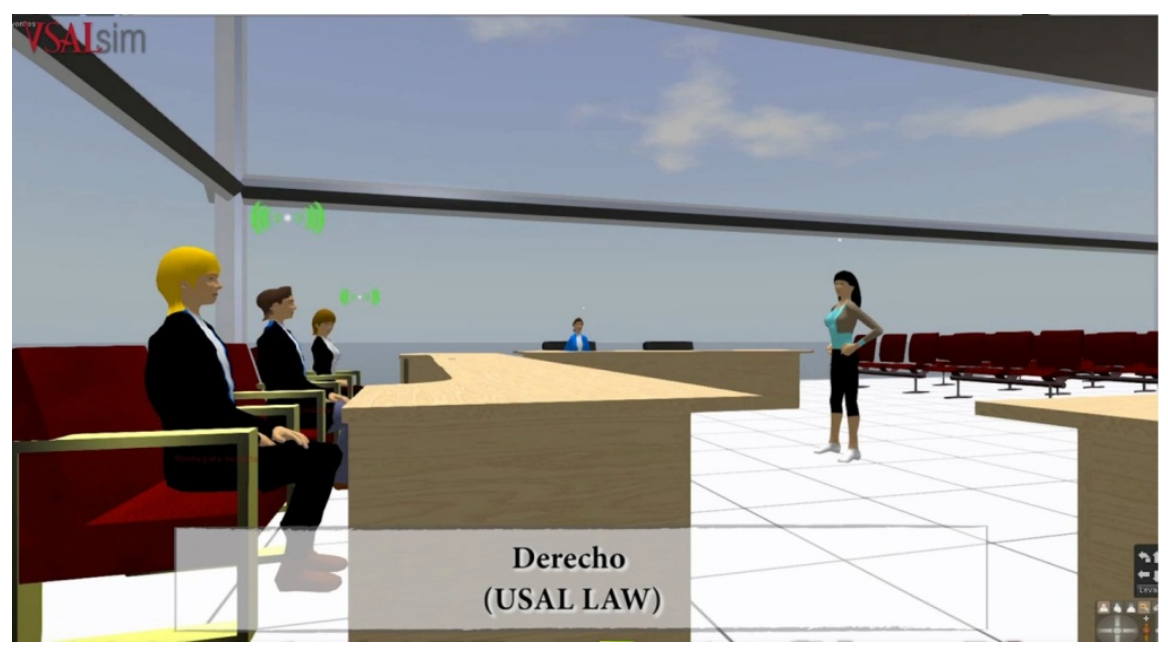

Fig. 2. View of virtual courtroom training

The integration of Moodle with USALSIM makes it possible to show presentations stored in the university's e-learning platform, link user profiles from both platforms to share the data of registered users, manage evaluation tests, and engage chats, etc. Tests are downloaded from the server and visualized through a set of text boxes in the virtual world. Once the test is completed, the USALSIM user is informed of the result and the Moodle platform saves all data related to the test (duration, score, etc.). Trainers can revise the performance of tests at any time, thus facilitating student assessment.

\section{Tests and Evaluation}

During the system validation, the following different professional situations were proposed:

Area of knowledge in Law: A professional situation in which students should debate whether specific court cases comply with Private International Law, and a trial simulation with different roles and phases of judicial process.

Area of knowledge in Chemistry: Two practical situations on security and good laboratory practices. 
Area of knowledge in Biology/Biotechnology: Two practices in histology and the treatment of kidney disease in mice.

Area of knowledge in Pharmacy: Two professional situations regarding technical inspections in laboratories and good laboratory practices.

Area of Humanities: Two practices related to the study of texts and theoretical research.

Area of Employability: Tutoring and workshops on self-employment and the employability of university students.

A group of 139 users (students and teachers or professionals) was selected to perform these different tasks (for a period of no less than eight hours). In the end, 86 of these individuals filled out questionnaires explaining their experiences and opinions about the system (design, usability, utility and possible application in their field of study). The distribution of these 86 individuals, who completed all activities, is shown in Figure 3.

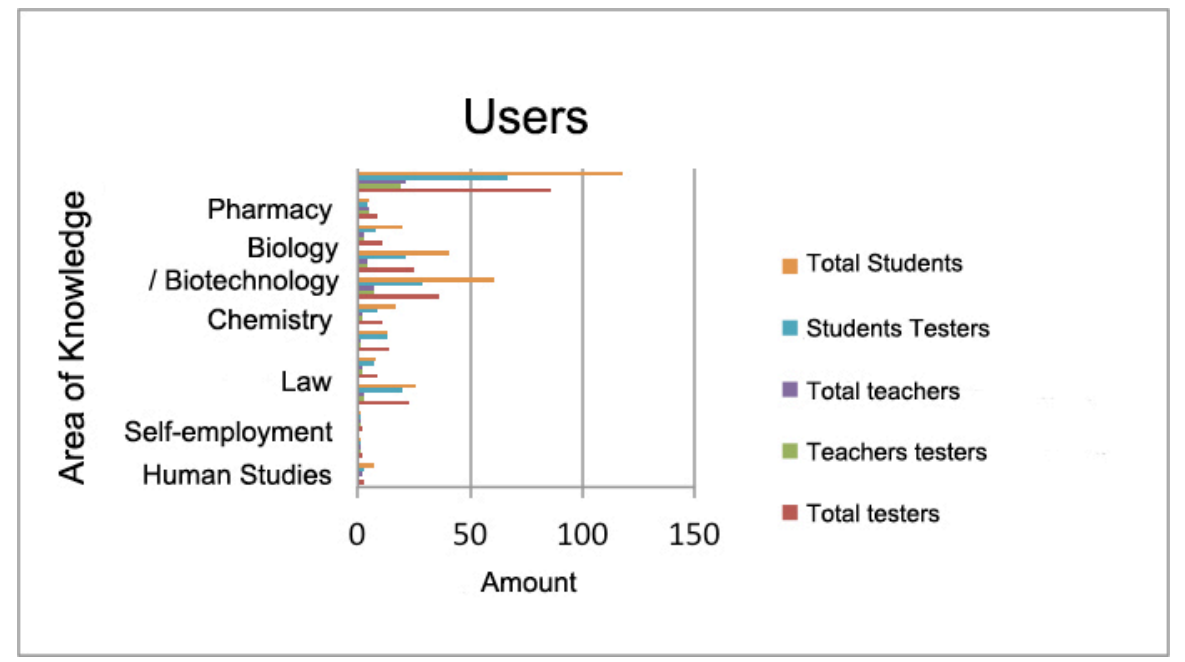

Fig. 3. Distribution of users testing the tool according to the activities carried out

The questionnaires, filled out by users, included various questions such as:

Was the software installation process simple?

Was the access to the simulator easy?

Was it easy to use the simulator (move, objects, etc.)?

Was the implementation of the practice easy to follow?

Did you find the simulator useful to do your work placement?

Would you like this simulator to be provided as a service by the University in a transversal way? 
Was it easy to design practices for students? (question for teachers and professionals).

Would you be willing to continue supporting the simulator development and testing?

Do you think the simulator is useful as a teaching tool? (exclusive question for teachers and professionals)

An example of the results of this analysis is shown in the attached graph, where 67 students assessed their satisfaction with the simulator using a score on a scale of 1 to 7 on a Likert scale (figure 4).

\section{Summary of Tool Evaluation by Trainers and Professionals}

The data analysis does not differentiate according to the nationality or age of the people that expressed their opinion. In the case of teachers and professionals, age could reveal that older persons may be less familiar with technological environments, indicating that certain assessments can be influenced by these parameters.

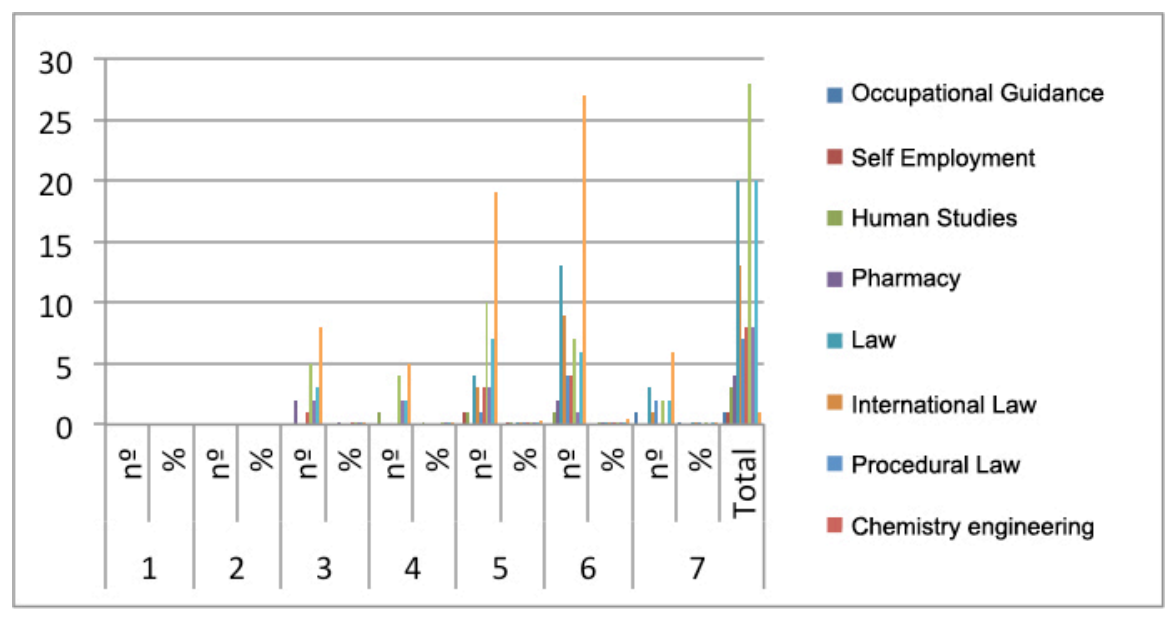

Fig. 4. Students Evaluation

Regarding the assessed data of teachers and professionals, the following comments can be deduced:

Regarding aspects such as ease of installation, ease of access, or navigation experience in the 3D environment: scores vary among the highest possible values, $(5$, $6,7)$, meaning that these test subjects (teachers and professionals) consider the installation, access and use of the system to be convenient and easy, and that it was well received.

Regarding the design and definition of work positions, opinions range between 3 and 7 , but with a high percentage $(42,1 \%)$ scoring $6 / 7$. 
Regarding usefulness, $42.1 \%$ considered the system is useful with a value of 6 in our Likert scale. The second most repeated value is $7 / 7$, with a percentage of $36.8 \%$.

In the next set of questions, regarding whether users think this system is useful as a cross-service of the University of Salamanca for teaching and work placement, or if they would like to continue developing the system, the opinion was unanimous. Teachers and professionals agree it is useful, they would like USALSIM to be a service offered by the University, and they would like to continue working within the project. These three questions have a $100 \%$ acceptance rate ("Yes" option).

\section{Summary of Tool Evaluation by Students}

The results of the student assessment are similar to the previous ones. Nationality and age were not recorded, although in this case there were foreign students and different ages (ranging from 18 to 45 ) represented.

As a summary of the collected data:

Regarding ease of installation, ease of use, or ease of access, all answers mostly range between the values 5,6 , and 7 . Students generally considered that the software is not very complex in the installation and configuration, and the use of the $3 \mathrm{D}$ environment is suitable and easy for them.

In terms of ease of managing, the opinions are more divided. In all cases the core values were $6(26.9 \%)$ and $7(28.4 \%)$. According to student feedback there are certain practices or professional positions that could be improved in terms of ease of use.

Students also evaluated the usefulness of the simulator for a real practice. In this case evaluations were generally positive, varying primarily between the values 4 , 5 and $7(20.9 \%, 28.4 \%$ and $25.4 \%$ respectively). Therefore, students consider the virtual system as valid for the completion of their internship or job positions.

With regard to usefulness of simulation in general, there was a satisfactory answer, with $70 \%$ of the values indicated as 5,6 or 7 .

Finally, students rated their overall satisfaction with the system, as a global evaluation related to the platform. Assessments were mainly concentrated in the 5-7 range of values (for $77 \%$ of the cases).

We can consider the first phase of the project to have been successful according to the feedback of the students who participated in the evaluation. Their positive opinions and suggestions allow us to improve USALSIM and go beyond our expectations

\section{Conclusions}

USALSIM was born as a local project of the University, hence the need to develop a cost-controlled proprietary software platform. For this reason the use of free 
software played an important role. Other virtual world platforms could have been adopted, such as Second Life, with stable versions and advanced technical support. However, according to the terms and conditions of the software agreement, any 3D construction and data in the platform would belong to the owners of Second Life, meaning that real and sensitive user data would not be under the control of the University. For these reasons, the University decided to select the open code of OpenSim, which allows user data (and complete data bases) to be stored in the local servers of the University. Additionally, there are no added costs related to the construction of each virtual 3D space, no Premium Services, and the access code is free and universal, being modified or adapted to the specific needs of the University.

After the development of the virtual space (which is summarized in this video http://www.youtube.com/watch? $\mathrm{v}=\mathrm{IFCce} 0 \mathrm{R} 5 \mathrm{qx} 0$ ), a number of tests were performed with real users. There were 139 participants: students from different areas of knowledge, as well as professors, counsellors, personnel associated with participating entities and companies, and other University staff. In this testing phase, users performed their assigned trainings and provided their opinion regarding the system through the use of questionnaires. The questions asked them to rate different aspects such as ease of installing the software needed to connect to the $3 \mathrm{D}$ virtual environment (connection client), ease of configuration, ease of navigation in the virtual environment, or ease of performing the training, in addition to suggestions for improvements. The evaluations from the student users were very positive, and reflect the achievement of all of the objectives indicated in section 2 . The vast majority approves the use of the simulator and consider the use of this technology as a convenient and advantageous way of complementing their studies. In addition to the students, a similar evaluation of this tool was provided by educators and personnel from the different participating companies. Their opinions have also been a great help for improving the system, and their assessment was very satisfactory.

USALSIM is a project with a clear goal of continuous improvement. New objectives and expansions have been defined for a short period, at technical and content level. The inclusion of other possible branches of knowledge, new professional skills, the integration of more institutions and business entities to provide work placements, etc., is under consideration, giving this platform a strong projection toward the future.

\section{References}

1. R. Schroeder (1996). Possible worlds: the social dynamic of virtual reality technologies. Boulder: Westview Press.

2. R. Schroeder (2008). Defining Virtual Worlds and Virtual Environments. Journal of Virtual Worlds Research, 1(1). January, 2009. 
3. D.A. Kolb, R.E. Boyatzis, C. Mainernelis. Experimental learning theory: Previous research and New Directions". Perspectives on Thinking, Learning and Cognitive Styles. R. J. Sternberg, L.F. Zhang (Eds.), Lawrence Erlbaum, Mahwah, NJ (2002), pp. 227-248

4. S. Barab, M. Thomas, T. Dodge, R. Carteaux, and H.Tuzun. Making Learning Fun: Quest Atlantis, A Game Without Guns," Educational Technology Research and Development, vol. 1, pp. 86-107, 2005.

5. B. Dalgarno, A. G. Bishop, W. Adlong, and J. Danny R. Bedgood, Effectiveness of a Virtual Laboratory as a preparatory resource for Distance Education chemistry students. Comput. Educ., vol. 53, pp. 853-865, 2009.

6. OpenSimulator: http://www.opensimulator.org [online] (Accessed 10 July 2013)

A. S. Tanenbaum, M. Van Steen (2008). Sistemas Distribuidos, principios y paradigmas ( $2^{\mathrm{a}}$ Edición). México, Pearson Educación

7. Moodle: http://www.moodle.org [online] (Accessed 10 July 2013)

8. Sloodle: http://www.sloodle.org [online] (Accessed 10 July 2013)

A. Konstantinidis, T. Tsiatsos, S. Demetriadis, A. Pomportsis, (2010). Collaborative Learning in OpenSim by Utilizing Sloodle. Telecommunications (AICT), 2010 Sixth Advanced International Conference on, vol., no., pp.90-95, doi: 10.1109/AICT.2010.75

9. Kemp, J. W., Livingstone, D. and Bloomfield, P. R. (2009), SLOODLE: Connecting VLE tools with emergent teaching practice in Second Life. British Journal of Educational Technology, 40: 551-555. doi: 10.1111/j.14678535.2009.00938.x

10. Cristina Pita Yáñez and Emiliana Pizarro Lucas, editors (2013) Cómo ser Competente. Cátedra de Inserción Profesional Caja Rural Salamanca, Universidad de Salamanca y Servicio de Inserción Profesional Prácticas y Empleo de la Universidad de Salamanca.

11. Estefanía Hernández-Fernaud, Yeray Ramos-Sapena, Fátima Negrín, Carmen Ruiz-de la Rosa, and Bernardo Hernández (2011). Empleabilidad percibida y autoeficacia para la búsqueda de empleo en universitarios. Revista de Psicología del Trabajo y de las Organizaciones, 27:131 - 142, 08.

12. Gerardo Castillo Ceballos and Alfredo Rodríguez Sedano (2011). De la universidad al puesto de trabajo. Ed. Pirámide. ISBN: 978-84-368-2517-6.

13. Murray Dalziel, Juan Carlos Cubeiro, and Guadalupe Fernández (1996). Las Competencias: clave para una gestión integrada de los Recursos Humanos. Deusto.

14. Laia Mestres i Salud (2013). Las competencias profesionales en el mercado laboral. http://www.educaweb.com/noticia/2011/03/28/competenciasprofesionales-mercado-laboral-4698/, 2011. R. E. (16).

15. Daniel Goleman (2012). Inteligencia emocional. Editorial Kairós SA.

16. Martha Alicia Alles (2005). Gestión por competencias: el diccionario. Ediciones Granica SA.

17. Accenture and Universia (2007). Las competencias profesionales de los titulados. Contraste y diálogo Universidad-Empresa. Madrid: Centro de Alto Rendimiento de Accenture y Universia. 
18. Margarita Martínez and Maribel Salvador (2005). Aprender a trabajar en equipo.

19. Anneleen Forrier and Luc Sels (2003). The concept employability: a complex mosaic. International journal of human resources development and management, 3(2):102-124.

20. Sebastián Rodríguez, Anna Prades, Lorena Bernáldez, and Sergio Sánchez (2010). Sobre la empleabilidad de los Graduados Universitarios en Catalunya: del diagnóstico a la acción. Revista de Educación, 351:107-137.

21. R Covey De Stephen (1999). Los 7 habitos de la gente altamente efectiva.

22. Serón, A. G. (1999). El enfoque de las competencias profesionales: Una solución conflictiva a la relación entre formación y empleo. Revista complutense de educación, 10(1), 335.

23. Zapata Ros, M. (2005). Secuenciación de contenidos y objetos de aprendizaje. Revista de Educación a Distancia.

24. Arechabaleta, M. G. (2005). Cómo desarrollar contenidos para la formación on line basados en objetos de aprendizaje.

25. Pizarro Lucas, E., Cruz Benito, J. (2012) USALSIM: Inserción Profesional, Prácticas y Aprendizaje en un Mundo Virtual. Buenas Prácticas de Empleabilidad de Estudiantes Universitarios. pp87-99. Universidad Miguel Hernández.

26. Second life. http://secondlife.com/whatis/ [online] (Accessed 10 July 2013).

27. Second life, terms of service. https://secondlife.com/corporate/tos.php [online] (Accessed 10 July 2013)

28. Craig W Thompson. Next-generation virtual worlds: architecture, status, and directions. Internet Computing, IEEE, 15(1):60-65, 2011.

29. Sa Wang, Zhengli Mao, Changhai Zeng, Huili Gong, Shanshan Li, and Beibei Chen. A new method of virtual reality based on unity3d. In Geoinformatics, 2010 18th International Conference on, pages 1-5. IEEE, 2010.

30. Unity 3D. http://unity3d.com [online] (Accessed 10 July 2013). 